\begin{abstract}
Iranica
Abstracta Iranica Revue bibliographique pour le domaine irano-aryen

Volume 34-35-36 | 2017

Comptes rendus des publications de 2011-2013
\end{abstract}

\title{
Y. Shalev, S.R. Martin. Crisis as Opportunity: Phoenician Urban Renewal after the Babylonians
}

\section{Astrid Nunn}

\section{(2) OpenEdition}

1 Journals

\section{Édition électronique}

URL : http://journals.openedition.org/abstractairanica/41610

DOI : 10.4000/abstractairanica.41610

ISSN : 1961-960X

Éditeur :

CNRS (UMR 7528 Mondes iraniens et indiens), Éditions de l'IFRI

\section{Référence électronique}

Astrid Nunn, «Y. Shalev, S.R. Martin. Crisis as Opportunity: Phoenician Urban Renewal after the Babylonians », Abstracta Iranica [En ligne], Volume 34-35-36 | 2017, document 51, mis en ligne le 15 juillet 2016, consulté le 02 octobre 2020. URL : http://journals.openedition.org/abstractairanica/41610 ; DOI : https://doi.org/10.4000/abstractairanica.41610

Ce document a été généré automatiquement le 2 octobre 2020.

Tous droits réservés 


\title{
Y. Shalev, S.R. Martin. Crisis as Opportunity: Phoenician Urban Renewal after the Babylonians
}

\author{
Astrid Nunn
}

\section{RÉFÉRENCE}

Y. Shalev, S.R. Martin. « Crisis as Opportunity: Phoenician Urban Renewal after the Babylonians ». Trans., 41, 2012, p. 81-100.

1 La destruction partielle de la fin de l'époque babylonienne a permis en Palestine et Phénicie une certaine restructuration "hippodamienne» de cités telles que Dor, Megadim, Beyrouth et al-Mina. Les AA. passent les origines du plan hippodamien en grille et son application dans le monde grec en revue. La dénomination de plan « hippodamien » au Proche Orient, où les plans en grille sont déjà bien attestés au Fer, les dérange. Ils y voient une restructuration plongée dans des racines locales et sans aucune perte d'identité. Cette discussion ne prend pas en considération une proposition déjà ancienne, selon laquelle Hippodamos - un Grec ionien de Milet - aurait lui-même été inspiré par les villes «ordonnées » d'Orient (E. J. Owens, The City in the Greek and Roman World, 1991, p. 11-31, p. 51-61). Qu'Hippodamos n'ait " que " mis en théorie ce que les urbanistes du Levant pratiquaient depuis des siècles et en conséquence la continuation d'une pratique locale restent plus probables qu'un retour d'influence grecque. 


\section{AUTEURS}

\section{ASTRID NUNN}

Université de Munich 